\title{
Carta a Desiderio Navarro ${ }^{1}$
}

\section{Letter to Desiderio Navarro}

\author{
Luis Rogelio Nogueras \\ Consuelo Méndez Tamargo \\ Nota preliminar \\ Preliminary Note \\ Universidad Nacional Autónoma de México \\ Instituto de Investigaciones Filológicas \\ consuelomt@unam.mx \\ orcid.org/oooo-0oo3-2452-7985
}

Resumen: Nota preliminar que introduce a la carta que Luis Rogelio Nogueras escribió a Desiderio Navarro en febrero de 1985, a partir de algunas reflexiones sobre la intertextualidad y el juego en su poesía.

Palabras clave: Luis Rogelio Nogueras, Desiderio Navarro, intertextualidad, poesía

Abstract: Preliminary note that introduces the letter that Luis Rogelio Nogueras wrote to Desiderio Navarro in Febrary 1985, based on some reflections on intertextuality and games in his poetry.

Keywords: $\quad$ Luis Rogelio Nogueras, Desiderio Navarro, intertextuality, poetry

Recibido: $\quad 2$ de octubre de 2020

Aceptado: 8 de noviembre de 2020

Luis Rogelio Nogueras, también conocido como Wichy el Rojo, nació en La Habana el 17 de noviembre de 1944. Escritor, poeta y guionista, murió el 6 de julio de 1985. Unos meses antes de su partida, el 29 de febrero, escribió una carta a Desiderio Navarro, carta que, en su brevedad, devela de mane-

1 La carta fue publicada como parte del dossier "Todos tenemos criterios", en La Gaceta de Cuba, núm. 5, sept.-oct. de 2017: 14, y como tributo a ambos escritores en <https:// neva.cubava.cu/2017/12/19/una-carta-de-wichy-el-rojo-para-desiderio-navarro/>, consultado por última vez el 18 de septiembre de 2020. 
ra extraordinaria algunas peculiaridades del remitente y del destinatario; en unas cuantas líneas podemos distinguir al poeta lúdico y al traductor y crítico severo.

En la carta, Nogueras felicita a Desiderio por la publicación de la reseña sobre el libro de un historiador del arte (al parecer, la exigencia crítica que lo caracterizó cayó con peso sobre el autor); el poeta lo alienta a continuar con su labor quijotesca en favor de la ciencia literaria y no ceder en su empeño, a pesar de las presiones y la falta de comprensión que siempre tuvo que enfrentar.

Tres meses después de su partida, Desiderio leía su artículo Intertextualidad, canon, juego y realidad histórica en la poesía de Luis Rogelio Nogueras, ${ }^{2}$ en el Fórum de Poesía, organizado por la Unión de Escritores y Artistas de Cuba (UNEAC). Ahí califica la poesía de Nogueras como "uno de los fenómenos más originales de la literatura cubana de la Revolución” (Navarro 2007: 293).

Si el contenido de la carta nos revela la calidad ética del personaje, la forma en que está escrita nos habla del poeta. Para tratar de entender su riqueza estilística, el análisis de Navarro brinda aspectos importantes sobre la intertextualidad y el juego en la poesía de Nogueras. Define la intertextualidad como el conjunto de "relaciones dialógicas que se establecen en un texto entre la palabra autoral y la palabra ajena", fenómeno en el cual distingue dos grandes tipos: el texto sobre el texto y el texto en el texto; de estos, nos interesan ahora los segundos, que utilizan componentes o estructuras de otro texto en su construcción, introduciendo la información metatextual de manera implícita (cf. Navarro 2007: 294-295). En esta línea, encuentra diferentes aspectos y composiciones que aluden a la obra de otro autor a través de diferentes recursos entre los que señala la "paráfrasis cómica" como una forma simple de referencia intertextual que no siempre se refiere a poemas, sino que también puede estar ligada a otro tipo de obras literarias. En la poesía de Nogueras, la conjunción del juego con la intertextualidad, señala Navarro, no siempre es un puro divertimento literario, ya que con frecuencia "no desempeña simplemente una función lúdicra, sino también una función de revaloración estética” (2007: 303), que puede ser de afirmación, cuando juega humorísticamente, o de negación, cuando lo hace a través de la parodia.

2 El artículo está firmado con fecha 16 de octubre de 1985; fue galardonado en 1988 con el Premio Nacional de Crítica Literaria "Mirta Aguirre" y publicado en 1986 en el número 154 de Casa de las Américas. Ahí especifica que se trata de la síntesis de un estudio más amplio que está en desarrollo (N. del A. 2007: 293). 
Hallamos así la alusión como una forma de construcción recurrente en la poesía de Nogueras, a través de la estilización o imitación, 3 que Navarro señala como una forma de "hacer referencia al modo de enfocar el tema o la actitud cosmovisiva que son propios del modelo imitado" (2007: 299). Nuestro autor está haciendo un guiño al traductor, a través del juego, característico de su personal estilo poético, por medio de la parodia del Finnegans Wake, escrito por James Joyce en París durante 17 años y publicado en 1939, dos años antes de la muerte del escritor en 1941. Aquí trataremos de esbozar brevemente solo dos aspectos de esta obra que consideramos que se relacionan directamente con nuestro documento y que pueden abonar a su mejor comprensión. Primero, el reto que ha significado su traducción y, después, la intertextualidad presente en él. Durante muchos años fue calificada como una obra intraducible; en sus 628 páginas Joyce experimenta con el lenguaje, creando una especie de "idioma políglota" en el que fusiona entre 60 y 70 diferentes lenguas de la más variada índole. ${ }^{4}$ Sin perder de vista que se trata de un documento privado, que después se hizo público, podemos apreciar mejor la simpleza y sencillez con que nuestro autor juega con las palabras, mediante pequeñas alteraciones, dejándolo todavía comprensible, para remitirnos al estilo creativo del Finnegans Wake de Joyce.

Lo primero que hay que observar es la intertextualidad presente en el Finnegans Wake. La primera y más conocida alusión está en el título, Finnegan's Wake es una balada cómica irlandesa de mediados del siglo XIX, que habla sobre "el velatorio de Finnegan", que a través de un juego de palabras después se convierte en "el despertar de Finnegan". En el primer capítulo, Joyce toma el argumento de la canción, relata la caída de un albañil que "se cae de una

3 Para Navarro, en la poesía de Nogueras "la estilización asume repetidamente una forma más bien rara en la poesía contemporánea: se trata de la 'imitación' como género o tipo de poesía, es decir, de lo que en otras culturas aún hoy se llama, sin connotaciones peyorativas, 'pastiche'. Estas estilizaciones de Nogueras toman como modelo el estilo de tal o cual poeta concreto" (299).

4 Existen diversos intentos de traducción al español: una de ellas es la traducción anotada de la primera página del escritor mexicano Salvador Elizondo; en 1992, el especialista español Francisco García Tortosa tradujo el capítulo ocho Anna Livia Plurabelle; el siguiente año, el francés Víctor Pozanco publicó su versión en un volumen de 300 páginas, la cual fue deshecha por la crítica. Casi 80 años después de su aparición, en 2016, la editorial El Cuenco de Plata, de Buenos Aires, publicó la traducción completa del argentino Marcelo Zabaloy, al parecer bastante plausible, aunque no deja de tener críticas que consideran que no recupera la agilidad y brillantez del original. Actualmente está en proceso una traducción íntegra en versión anotada del mexicano Juan Díaz Victoria. 
escalera y se rompe la cabeza. En su velatorio, los asistentes bailan, se emborrachan y se pelean, de suerte que un chorro de whisk[e]y rocía su cadáver y lo devuelve a la vida para unirse a la celebración” (Belda s. f.). Wiskey proviene del irlandés uisce beathadh, "agua de vida", el licor que lo mata lo devuelve a la vida; de esta manera significa Joyce el tiempo circular, vida/muerte/vida, presente en toda la obra. Las alusiones a libros clásicos como la Biblia, el Corán, el Libro de los muertos, o la leyenda de Tristán e Isolda, así como obras de Shakespeare, Lewis Carroll o Giambattista Vico, solo por nombrar algunos, incluidos el Ulises y El retrato del artista adolescente, del mismo Joyce, aparecen a lo largo de los cuatro libros; a decir de Zabaloy (Razo 2019), se trata de una recreación de la literatura que leyó durante toda su vida. 5 En la carta de Nogueras aparece la intertextualidad en referencias literarias simples que remiten a conceptos implícitos que podrían definir la personalidad de Navarro. Encontramos alusiones a textos de la literatura, como al idealista Don Quijote, o a la Leyenda del Santo Grial, de la novela caballeresca. A personajes como el filósofo y orador Cicerón; a Jesús, en Lucas 4:24; al lingüista Vladimir J. Propp y al trompetista estadounidense de jazz John Birks Gillespie, más conocido como Dizzy Gillespie.

Las intersecciones entre Wichy y Desiderio seguramente son muchas más, y, como señala el propio Navarro, tal vez en este campo casi todo esté por descubrirse, analizarse o explicarse; aquí solo esbozamos una mínima parte. Conociendo el vasto repertorio de lenguas que traducía Desiderio y su admiración por Joyce, me pregunto si habrá incursionado en la traducción del Finnegans Wake.

\section{Bibliografía}

BeldA, Ismael. "Lectores contra el monstruo: el periplo de Finnegans Wake", Revista de Libros. Segunda época, en <https://www.revistadelibros.com/articulo_imprimible.php?art=5347\&t=articulos $>$, consultado por última vez el 20 de septiembre de 2020 .

5 Son tantas las referencias y alusiones que, en 1974 James S. Atherton, publicó una edición revisada de su libro Books at the Wake: A Study of Literary Allusions in James Joyce's Finnegans Wake, donde recopiló gran parte de ellas. También existe el sitio web Finnegans Wake Extensible Elucidation Treasury (fweet.org), donde se concentra la mayor cantidad de referencias, alimentado por estudiosos y lectores que proponen notas a los administradores del sitio ( $c f$. Vázquez 2017). 
NaVARro, Desiderio ([1985] 2007). "Intertextualidad, canon, juego y realidad histórica en la poesía de Luis Rogelio Nogueras”, Ape(n)sar de todo. Para leer en Contexto. La Habana, Instituto Cubano del Libro/Editorial Letras Cubanas: 293-308.

Nogueras, Luis Rogelio ([1985] 2017). Dossier “Todos tenemos criterios”, en La Gaceta de Cuba, núm. 5, sept.-oct.: 14.

Quintana, Nevalis (2017). Carta de Luis Rogelio Nogueras a Desiderio Navarro, en <https://neva.cubava.cu/2017/12/19/una-carta-de-wichy-el-rojo-para-desiderio-navarro/>, consultado por última vez el 18 de septiembre de 2020.

Razo, Praxedis (2019). “Finnegans Wake en un espejo”, La Razón. México, en <https:// www.razon.com.mx/el-cultural/finnegans-wake-en-un-espejo/>, consultado por última vez el 21 de septiembre de 2020 .

VÁzQuEz, Cristian (2017). "Finnegans wake, las traducciones del libro intraducible”, Revista Letras Libres, en <https://www.letraslibres.com/espana-mexico/ revista/finnegans-wake-las-traducciones-del-libro-intraducible>, consultado por última vez el 18 de septiembre de 2020 .

\section{Consuelo Méndez Tamargo}

Maestra en Lingüística Aplicada y licenciada en Periodismo y Ciencias de la Comunicación por la Universidad Nacional Autónoma de México. Obtuvo la especialidad académica en televisión educativa del Institut National de L’Audiovisuel, en Bry sur Marne, Francia. Sus líneas de investigación incluyen la hermenéutica literaria y la hermenéutica de las artes, especialmente enfocadas en la adaptación literaria al cine. Coordinó la edición y compilación del libro Miradas semióticas, publicado por el CELE-UNAM (2017). Editora del dossier Hermenéutica del cine en Interpretatio. Revista de Hermenéutica, 3-2, sep. 2018-feb. 2019. Ha participado en numerosos foros académicos nacionales e internacionales. Actualmente es académica de tiempo completo del Seminario de Hermenéutica del Instituto de Investigaciones Filológicas de la UNAM. 
La Vana, juegues 29 de fiebrero, 1985

Soñar Desiférreo Navajo

Quejido Desiférreo

Leí con enarma placifer tu resueña sobre el soporífero librium del licenciado en Histeria del Harte e investimador de ignografía compañuelo...Nalgunos acanémicos de nuestropajo medio gutural no te perdonarán que hayas bejado de su altar (ego) a un santo (traficante) del rengo de tal......colmo tanloco te perdonaron en su memento tus artílocos contra excretores cuvagos............. En lo que a mí respeta, tengo la más absolucra seguridad de que tú no ganas ni un solo sentado por tu infaticables trabados en pro de un mayor rigor científrico (es decir, contra la cienfría lateraria de diantres para fuera). Hay mochos charlatintas en nuestra críptica litegraria, pero contra ellos tú, cual nuevo Don Cojones de la Marcha, te lanzas con tu afialada pluma.

No desmales en tu lodable empuño. Sigue tu pequeño comino en pas del Santo Grial de la ciencia literari. Puede obscurrir que negros nubarrones traten de frenar tu trabado; incluso asordarán en tu horisanto cabayerros ponderosos del mundo cifilizado de las lepras...que descargen sobre ti el pozo (ciego) de su ira. Pero tú no hagas craso de ellos. Recuerda la tan alarbeada y gastada fraseada (de piso) de Cincerón. "Nadie es trompeta en su tierna”, ni siquiera Dizzie Guillespie. Dice Prop que la igneaginación del serdo humano es limitarada; sin embargo, la estupidez, la envidia y el odio al que sabe más de cuatro coplas no tienen límites.

\{...\} hay barios (Ba) profezoreos \{...\} que te detestan, porque tú los pones en rídiculo. iPero no es verdad que tú los culoques en ridículo, porque en ese sitio ellos están culocados hace mucho tiemplo!

Tu admirador sincerlo.

L. R. Nogales.

P.D. Perdona esta parodia del inimitravel estío de aquel viajero solitario del nuevo lenjuague que fue J. Joke en su cerebrado libruma Finnegans Wake, wave? 